\title{
Suitability of the electromagnetic ring expansion test to characterize materials under high strain rate deformation
}

\author{
Kang Yang ${ }^{1}$, Geoffrey Taber ${ }^{2}$, Thaneshan Sapanathan ${ }^{1,}$, , Anupam Vivek ${ }^{2}$, Glenn S Daehn², Rija Nirina Raoelison ${ }^{1,3}$, \\ Nicolas Buiron ${ }^{1}$ and Mohamed Rachik ${ }^{1}$ \\ ${ }^{1}$ Sorbonne universités, Université de Technologie de Compiègne, Laboratoire Roberval, CNRS UMR 7337, Centre de recherche Royallieu, \\ CS 60319, 60203 Compiègne cedex, France \\ ${ }^{2}$ Department of Materials Science and Engineering, The Ohio State University, 2041 College Road, Columbus, OH 43210, USA \\ ${ }^{3}$ Université de Bourgogne Franche Comté, IRTES-LERMPS, Université de Technologie de Belfort Montbéliard, 90100 Belfort, France
}

\begin{abstract}
Characterisation of materials under high strain rate is always challenging, and requires sophisticated apparatus. Magnetic pulse forming techniques can involve high strain rate deformation and the electromagnetic ring expansion test (ERET) is considered here to determine its suitability to characterise materials at high strain rate. The multi-physics and high speed nature of the process requires advanced numerical modelling techniques to gain insight and understanding of stress development when used as a material characterisation technique. In order to evaluate the suitability of the ERET to fully characterise the material behaviour at high strain rate, stress states were investigated using 3D coupled mechanical-electromagnetic simulations on a validated numerical model. The numerical simulations were performed in LS-Dyna ${ }^{\circledR}$ with a modified Johnson-Cook (MJC) material model in this study. Albeit the preliminary results show the development of biaxial stress during the test, a shielding mechanism is proposed to eliminate the axial component of the stress on the rings. This study indicates that the ERET has a potential to be used for characterisation of the material parameters under the influence of high strain rate.
\end{abstract}

\section{Introduction}

In general, manufacturing processes such as forging, forming, stamping and cutting are typically involved with strain rate of $10^{2}-10^{4} s^{-1}[1]$. Further increase in strain rate is experienced by materials under high speed manufacturing processes such as electromagnetic pulse forming [2-4] and electromagnetic pulse welding [5-14], vaporising foil actuator welding [15-17], friction stir processing [18-20], explosive welding [21], and other high speed impact conditions like explosion or cold spray processing [22, 23]. Material characterisation at high strain rate also requires precise measurement techniques to capture the behaviour within the short duration of a mechanical test [1].

The present study proposes and evaluates the suitability of an electromagnetic ring expansion test (ERET) to be used in the characterisation of material under high strain rate conditions including the damage behaviour. The ERET is based on a ring expansion which is facilitated by the Lorentz force due to the change in magnetic field. Furthermore, this technique could especially be suitable for the characterisation of tube materials that contain residual stresses created during the fabrication of tubes from sheet metals.

In order to fully characterise a material, one should consider capturing the elasto-plastic and damage

\footnotetext{
${ }^{\mathrm{a}}$ Corresponding author: thaneshan.sapanathan@utc.fr
}

behaviours of the material under the exact nature of the process condition. A material characteristic could be simply altered by the working conditions of temperature and strain rate. The stress state, that can be interpreted based on Lode angle parameter and triaxiality, play a major role in damage behaviours of a material [24-26]. In order to investigate the suitability of the ERET for material characterisation, the stress state has been investigated in this study for various scenarios of the test. Triaxiality and Lode angle parameters are important, and require being consistent during the damage to determine the fracture strain of a material to treat it as a one dimensional tensile test.

A validated coupled mechanical-electromagnetic 3D model has been used under various conditions to evaluate the stress cases during the ERET. The validation step of the model is also described and the experimental result shows reasonable agreement with the numerical simulation. The coupled simulations performed with LSDYNA $^{\circledR}$, which uses both finite element method and boundary element to solve such problems. The preliminary predictions indicate that the ring experiences bi-axial stresses resulted from radial and axial components of the Lorentz forces. However, minimising the height of the ring reduces the influence of biaxiality of the stress state that cannot eliminate the longitudinal component of the compressive stress on the rings. 
Therefore, this study has been extended by using a shielding mechanism to control the axial component of stress experienced by the ring, which is promising for the characterisation of materials under high strain rate condition in a uniaxial fashion.

\section{Materials and method}

\subsection{Experiment design}

Applied source current in a helix coil creates the required magnetic field and Lorentz force during electromagnetic forming processes. In this case, the coil was designed to be fixed and made of copper alloy $\mathrm{Cu}-\mathrm{Zr}-\mathrm{Cr} 18150$ with a cross section of $6.35 \mathrm{~mm} \times 6.35 \mathrm{~mm}$. This helix coil has 5 turns with a helix pitch of $8 \mathrm{~mm}$. It has an inner diameter of $25.45 \mathrm{~mm}$. A schematic illustration of the coil used in this study is shown in Figure 1.

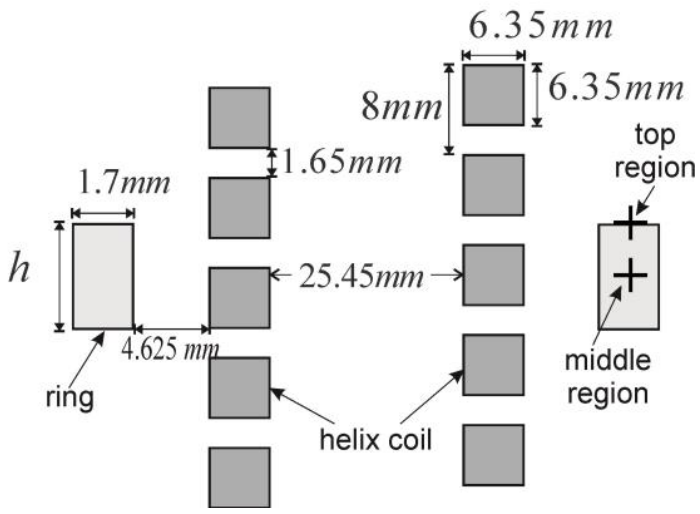

Figure 1. Schematic illustration showing the cross-section of the electromagnetic ring expansion setup.

The expansion ring used in the simulation was made of aluminum alloy Al 6061 - T6 with an inner diameter of $47.4 \mathrm{~mm}$ and thickness of $1.7 \mathrm{~mm}$. In order to analyse the influence of height on the stress state, 3 different heights (h in Figure 1) of the ring were chosen with $3.2 \mathrm{~mm}, 6.4$ $\mathrm{mm}$ and $9.6 \mathrm{~mm}$.

An experimental case with $6.4 \mathrm{~mm}$ height of the ring was used to validate the model. The experiment was performed at Ohio State University with the aluminum rings made from Al 6061-T6 tube stock. Figure 2 shows the design of the helix coil with leads, which is potted with epoxy in a fiberglass tube. Leads of the same material were brazed to the helix. The velocity was measured using photonic Doppler velocimetry (PDV) system [27]. The experimental current flow through the cross section of the helix was measured using Rogowski coil and used in the numerical simulations. The time versus current evolution is shown in Figure 3.

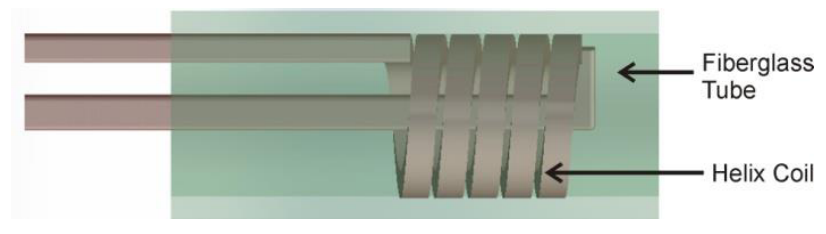

Figure 2: An illustration showing the helix coil inside a fiberglass tube.

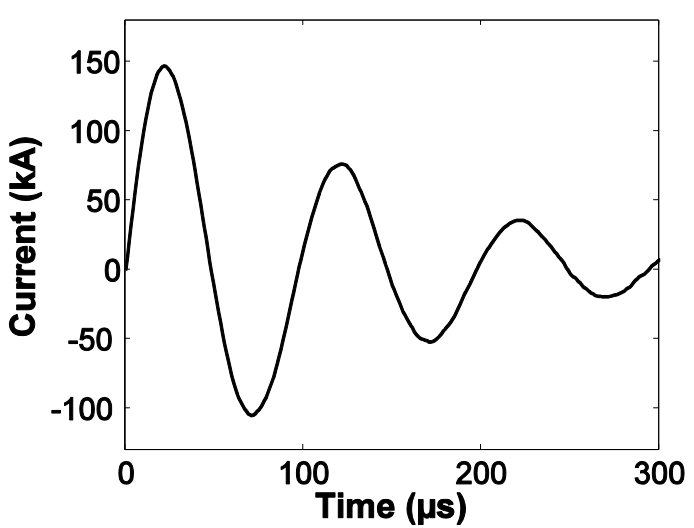

Figure 3: Current flow in the expansion coil.

From preliminary simulations, it was identified that the stress states are not the same at various locations of the ring due to the uneven distribution of the Lorentz force on the ring. The stress states of top and middle regions of the ring are used to explain the development of stresses during a ring expansion test and the suitability to use the test for high strain rate material characterisation.

Later models are used with a controlling mechanism using shield blocks to eliminate the development of compressive stress during the ERET. The controlling shield blocks setup is shown in Figure 4. The shield used in this study consists of two thick ring shapes made of copper and fixed in place during the simulations (i.e. the deformation on these shield blocks are neglected and considered to be used here to block the vertical force components acting on the ring). The main function of the shield is to eliminate magnetic fields in the radial direction, thus the compressive Lorentz force on the ring is minimized. More explanation on this topic is included in Section 3.3.

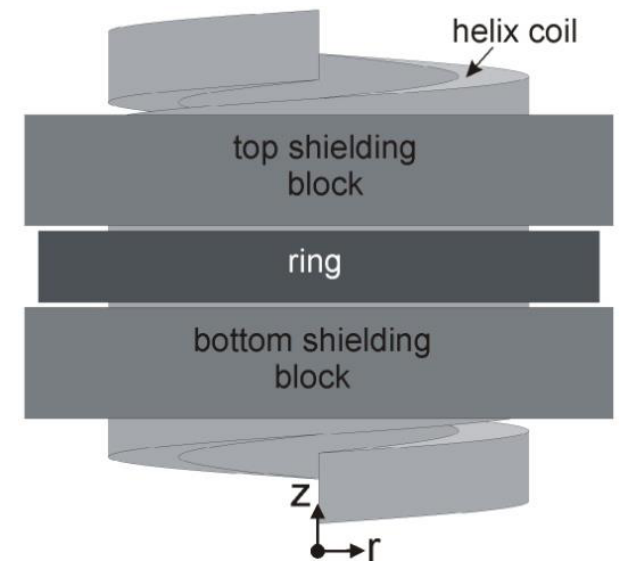

Figure 4. Numerical simulation interface showing the shield set up used in the ring expansion test.

\subsection{Simulation method}

A coupled mechanical-electromagnetic numerical simulation was carried out to investigate the development of stresses during the ring expansion test. This simulation used LS-DYNA numerical package with integrated solver version R8 [28]. 
Based on Maxwell's equations and Biot-Savart's law, a combined finite element method (FEM) with boundary element method (BEM) is used during the calculation of magnetic field and Lorentz forces in LS-DYNA [29]. BEM is used to compute the surface current and electromagnetic field thus the magnetic field in the air is not required in LS Dyna ${ }^{\circledR}$ simulations. FEM is used during the computation of eddy current and Lorentz force in the ring. At each electromagnetic time step, the electromagnetic and mechanical computations are coupled.

In order to implement the constitutive behavior of the material in the model a modified Johnson-Cook model [28] was chosen as expressed in Equation 1.

$$
\bar{\sigma}=\left(A+B \bar{\varepsilon}^{n}\right)\left[1+\left(\frac{\dot{\bar{\varepsilon}}}{\dot{\overline{\varepsilon_{0}}}}\right)\right]^{c}\left(1-T^{* m}\right)
$$

where, $\bar{\sigma}$ and $\bar{\varepsilon}$ are the von Mises equivalent stress and strain respectively, $\dot{\bar{\varepsilon}}$ is the strain rate. Here $\dot{\bar{\varepsilon}}_{0}$ is equal to $1 / s$ and $T^{*}$ is a dimensionless temperature parameter. $A, B, C, n$, and $m$ are constants, obtained from literature, given in Table 1 [30]. The coil was fixed and set as rigid in the model.

Table 1. Johnson-Cook parameters of Al 6061-T6

\begin{tabular}{|c|c|c|c|c|c|}
\hline $\begin{array}{c}\text { Johnson- } \\
\text { Cook } \\
\text { parameters }\end{array}$ & $A(\mathrm{MPa})$ & $B(\mathrm{MPa})$ & $C$ & $n$ & $\mathrm{~m}$ \\
\hline $\begin{array}{c}\text { Numerical } \\
\text { values }\end{array}$ & 324 & 114 & 0.002 & 0.42 & 1 \\
\hline
\end{tabular}

The influences of both temperature increase and high strain rate are considered in this model. However, the electrical conductivity change due to the temperature increase is neglected in this present work. Longitudinal and transverse views of the meshed model used in the simulation are respectively shown in Figure $5 \mathrm{a}$ and $5 \mathrm{~b}$. The model used solid 8 nodes brick elements for both coil and the expansion ring. The element size is $0.8 \mathrm{~mm}$ in height and $0.57 \mathrm{~mm}$ in thickness, which is smaller than skin depth $0.7 \mathrm{~mm}$ in this case. Details of the skin depth can be found elsewhere [31]. It is also ensured to capture the electromagnetic skin depth effect during the simulation.

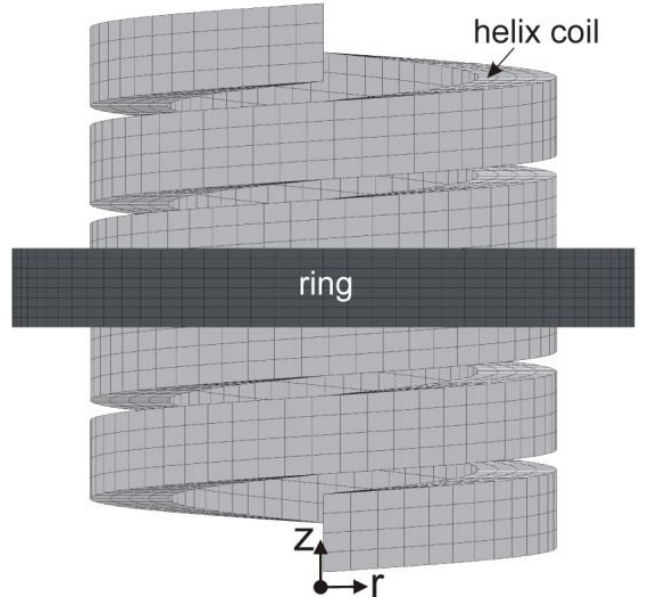

(a)

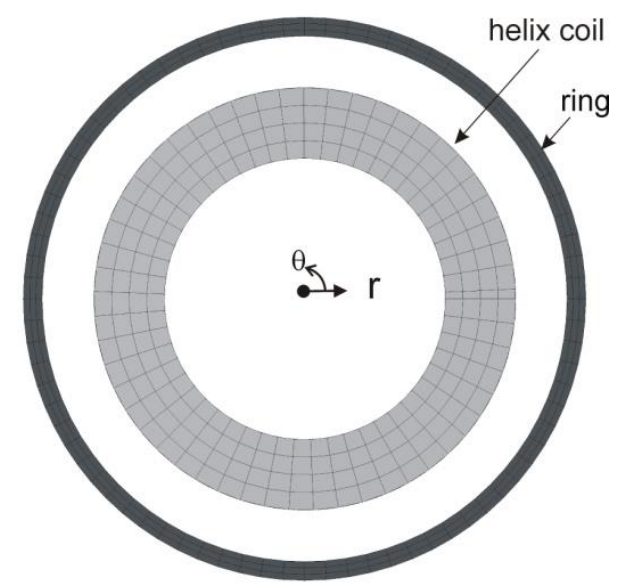

(b)

Figure 5. Meshed model with the $6.4 \mathrm{~mm}$ height ring used in preliminary investigation without shielding blocks, views along a longitudinal (a) and a transverse (b) planes.

\subsection{Material}

The electromagnetic ring expansion test has a multi physics nature which requires effective coupling between mechanical, electrical, magnetic and thermal components.

Physical quantities of the Al 6061-T6, the density, Young's modulus, Poisson's ratio are respectively set as $2700 \mathrm{~kg} / \mathrm{m}^{3}, 68.9 \mathrm{GPa}$ and 0.33 . Electromagnetic and thermal properties of both the ring and the coil are given in Table 2.

Table 2. Electromagnetic and thermal properties of the components

\begin{tabular}{|c|c|c|c|c|}
\hline $\begin{array}{c}\text { Part } \\
\text { name }\end{array}$ & $\begin{array}{c}\text { Electrical } \\
\text { conductivity } \\
(\mathrm{S} / \mathrm{m})\end{array}$ & $\begin{array}{c}\text { Thermal } \\
\text { conductivity } \\
(\mathrm{W} / \mathrm{m} \cdot \mathrm{K})\end{array}$ & $\begin{array}{c}\text { Specific } \\
\text { heat } \\
\text { Capacity } \\
(\mathrm{J} / \mathrm{kg} \cdot \mathrm{K})\end{array}$ & $\begin{array}{c}\text { Melting } \\
\text { temperature } \\
(\mathrm{K})\end{array}$ \\
\hline $\begin{array}{c}\text { Coil } \\
\text { and } \\
\text { shield }\end{array}$ & $5.62 \times 10^{7}$ & 377 & 390 & 1356 \\
\hline Ring & $2.51 \times 10^{7}$ & 230 & 880 & 933 \\
\hline
\end{tabular}

\section{Results and Discussion}

\subsection{Validation of numerical simulation}

Figure 6 shows the comparison between predicted and measured velocities for the case of $6.4 \mathrm{~mm}$ height. Although fracture occurs at the time of $\sim 100 \mu$ s during the experiment while the damage parameters are not yet included in the present study, this model still can be used to investigate the stress state during the ring expansion process. Thus, the simulation was carried out for the first $100 \mu \mathrm{s}$.

The simulation result shows a good agreement with the experiment. Nevertheless, the comparison shows a 
deviation of $10 \%$ in the maximum velocity, the tendency is well captured during the simulation. This could be due to high strain rate effect, while the aforementioned Johnson-Cook parameters may fail to represent the accurate behavior of the material. This is also in agreement with another study, where lower energy cases (i.e. lower strain rate case) agree well compared to higher energy cases for same material parameter [32]. This situation also highlights the definite requirement of the material calibration for respective strain rates. More information on the material calibration using ring expansion test could be found elsewhere [32-35].

The discrepancy could also arise from the numerical conditions such as mesh convergence and the time step used in this study. In this present study a single point PDV was used, the results could also be improved using multipoint PDV system for this measurement to improve the accuracy.

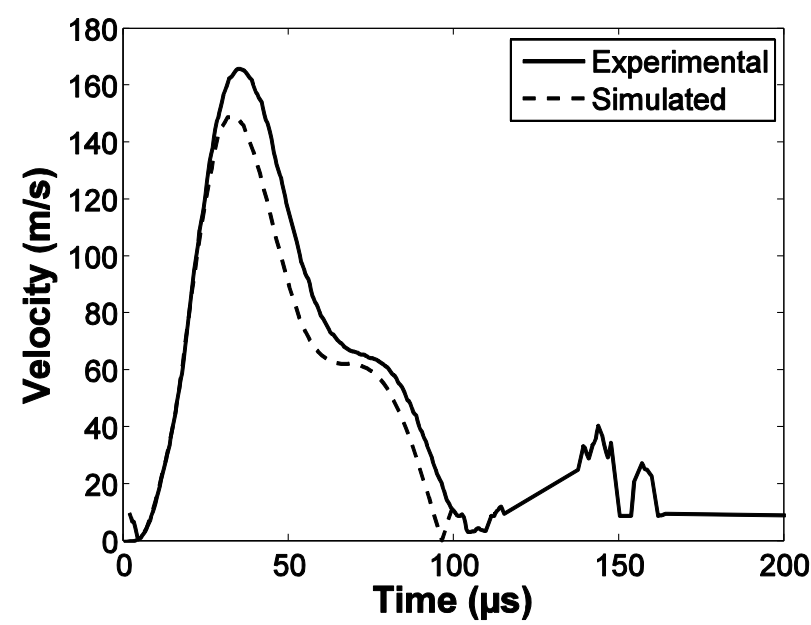

Figure 6. Comparison of experimental and simulated radial velocity

\subsection{Stress state analysis of the ring during preliminary simulation}

During the ring expansion, the radial component of the force drives the deformation and causes angular stress component in the ring. In ERET, there exists compression force along the longitudinal direction which makes the case as biaxial. Both the radial and longitudinal components of Lorentz forces are proportional to the square values of the input current, but due to the longitudinal symmetry of the force, this test allows to have only radial motion of the ring. Besides, the longitudinal compression force is a body force so that has varying influences on the top (or bottom) and middle region of the ring. Therefore, in order to study the stress state, the middle and top regions of ring are considered separately.

In order to study the damage behavior of materials, one could consider investigating Lode parameter and triaxiality [28]. Therefore, these parameters are carefully investigated for the test to determine the suitability of the ERET for material characterization. These parameters are computed from Cauchy stress tensor $\boldsymbol{\sigma}$ and the stress deviator $\mathbf{S}$ using the Equations 2-4.

$$
\begin{gathered}
\mathrm{I}_{1}=\operatorname{tr}(\boldsymbol{\sigma}) \\
\mathrm{J}_{2}=\frac{1}{2}\left[\operatorname{tr}\left(\boldsymbol{\sigma}^{2}\right)-\frac{1}{3} \operatorname{tr}(\boldsymbol{\sigma})^{2}\right]=\frac{1}{2}\|\mathbf{S}\|^{2} \\
\mathrm{~J}_{3}=\operatorname{det}(\mathbf{S})
\end{gathered}
$$

The Lode parameter $\xi$ is defined by Equation 5 .

$$
\xi=\frac{\sqrt{27}}{2} \frac{\mathrm{J}_{3}}{\mathrm{~J}_{2}{ }^{\frac{3}{2}}}
$$

The Lode parameter shows the relationship between shear stress and compression or tensile stress, when $\xi=1$, $\xi=0$ and $\xi=-1$ respectively indicates an expansion case, a pure shear case and a compression case.

The triaxiality $\Gamma$ is defined by Equation 6 . The triaxiality is used to determine the complexity of stress cases, where $\Gamma=0.33$ indicate a uniaxial tensile test case. Figure 7 shows the map of triaxiality and lode parameter variance for various tests and stress cases [36].

$$
\Gamma=\frac{\mathrm{I}_{1}}{3 \sqrt{3 \mathrm{~J}_{2}}}
$$

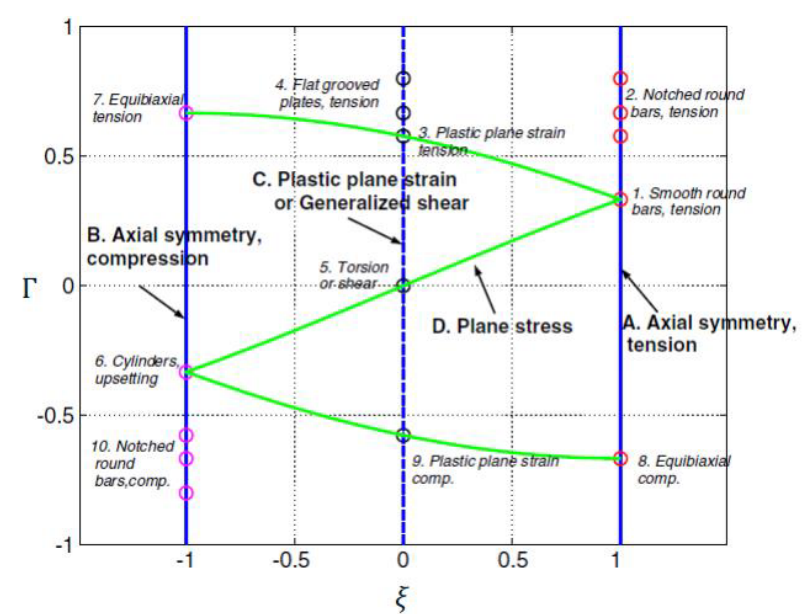

Figure 7. Triaxiality and Lode parameter variance for various test cases [36].

The Lode parameter versus plastic strain for the middle and top regions of the ring are respectively shown in Figure $8 \mathrm{a}$ and $8 \mathrm{~b}$. During the simulation, the ring with $9.6 \mathrm{~mm}$ height only reach $\sim 15 \%$ plastic strain because it requires more energy for its expansion than that of other rings with shorter height. 


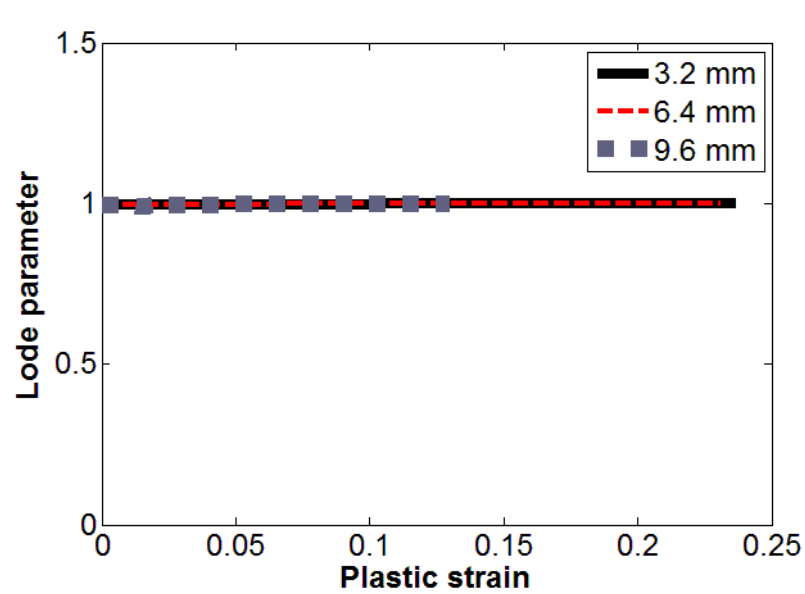

(a)

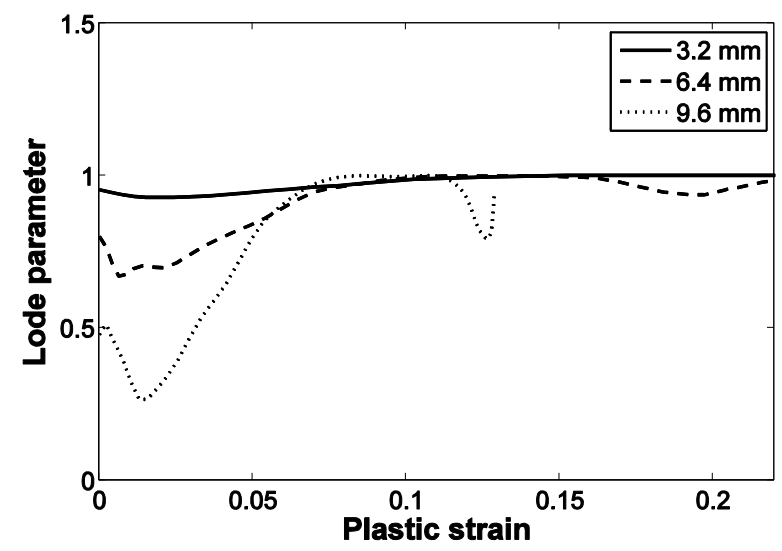

(b)

Figure 8. Lode parameter against equivalent plastic strain for each case on the top region (a) and the middle region (b) of the ring.

Figure 8a shows, the Lode parameter is always equal to 1 at the top region of the ring, which signifies that the stress development in the top region of the ring is similar to an axial symmetric tensile mode (Figure 7). The bottom side of the ring also has the similar results due to the symmetry.

In contrast, Lode parameter varies in the middle region of the ring (Figure $8 \mathrm{~b}$ ), while $9.6 \mathrm{~mm}$ height ring shows the maximum variation $(\sim 0.3$ to 1$)$ and $3.2 \mathrm{~mm}$ height ring has the minimum variation in comparison among these 3 cases. It is clear that due to the magnetic field decrease from the middle towards both top and bottom ends of the ring that significantly influences the stress development at various locations of the ring during the ERET. This difference also increases with the increase in ring's height. Consequently, the ERET with smaller height of the ring better represents a pure (radial) compression or expansion stress case.

Figure 9a shows triaxiality parameter of the top region that varies between 0.23 and 0.34 , which covers close to the value 0.33 . Combine with the Lode parameter property, the stress on the top and bottom of the ring could be considered as similar to a case of uniaxial tension on smooth round bars (Figure 7). The triaxiality of $9.6 \mathrm{~mm}$ ring shows more closeness to 0.33 among these three heights because of the role of compressive
Lorentz force caused by the radial component of magnetic field. This radial magnetic field on the top surface of $9.6 \mathrm{~mm}$ ring is smaller than that of other cases that leads to have minimum compressive force among these 3 cases.

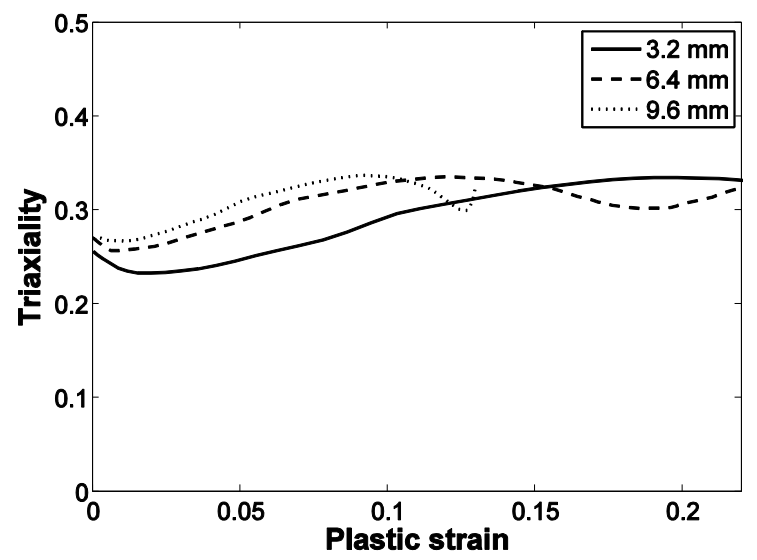

(a)

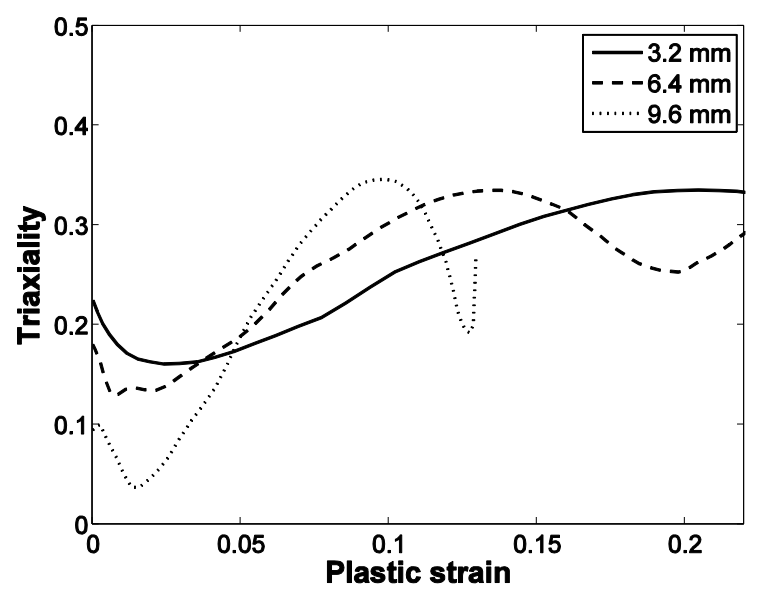

(b)

Figure 9. Triaxiality in each case on the top region (a) and middle region (b) of the ring.

Triaxiality in the middle of the ring (Figure 9b) varies between 0.03 and 0.35 in different cases. The compressive Lorentz force is also a body force. As a result, the longitudinal compressive stress on the top or bottom of the ring is negligible while it is comparable to the angular expansion stress in the middle region of the ring. This force also significantly influences the rings with large height, which bears more force and experiences a very unstable triaxiality.

According to the aforementioned results, the stress state of top and bottom regions of the ring shows a close connection with a uniaxial tensile test case while the stress state of middle region indicates a complex scenario; $3.2 \mathrm{~mm}$ height indicates closeness with tensilecompressive stress case and $9.6 \mathrm{~mm}$ height shows tensilecompressive-shear stresses.

\subsection{Improvement of stress state towards uniaxial using shield blocks}

A control mechanism using shield blocks is proposed and investigated to improve the stress state by eliminating the 
axial compressive Lorentz force components on the expansion ring. A $6.4 \mathrm{~mm}$ height ring sample is investigated in this simulation using the model described in Figure 4 to evaluate the proposed shielding mechanism.

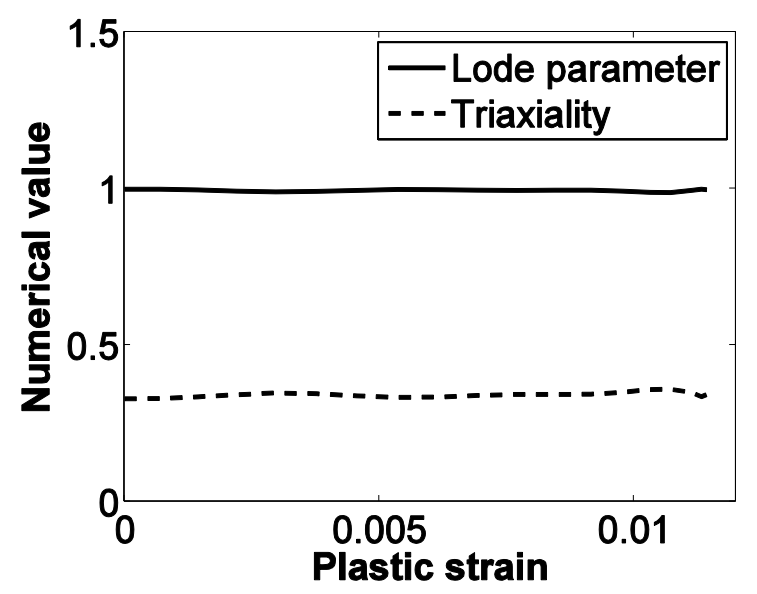

Figure 10. Triaxiality and Lode parameter in the middle region of $6.4 \mathrm{~mm}$ height ring with shields with the input current shown in Figure 3.

Figure 10 shows that the triaxiality is more stable and close to $0.33(\sim 0.32-0.35)$ and Lode Parameter is always equal to one for the entire simulation with the shield blocks. The results indicate that the shielding mechanism eliminates the radial component of the magnetic field which creates the compressive Lorentz force in previous cases. Therefore, stress state obtained in this case of electromagnetic ring expansion test agrees well with a uniaxial tensile test case. Therefore, the ERET with the proposed shielding mechanism could be considered to characterise materials in a similar manner to a tensile test with the implemented role of high strain rate behaviour.

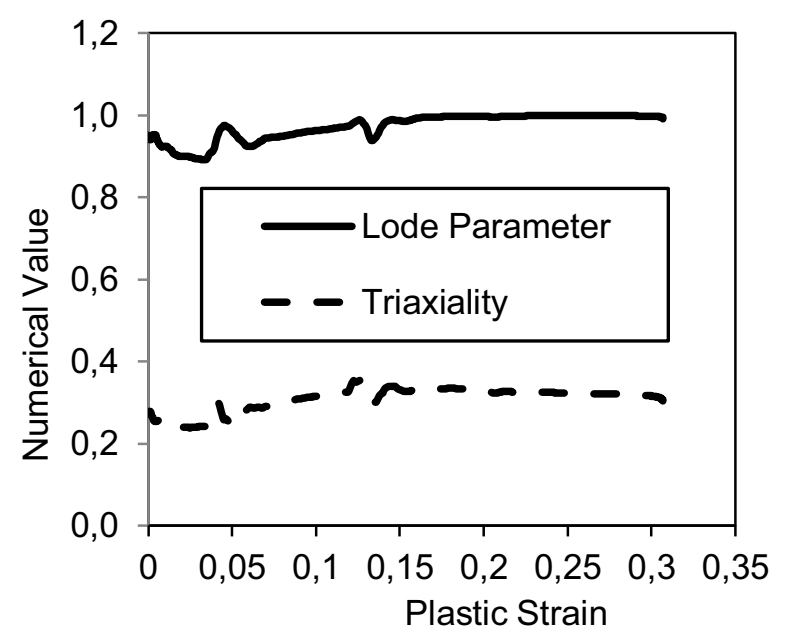

Figure 11. Triaxiality and Lode parameter in the middle region of $6.4 \mathrm{~mm}$ height ring with shields with an increase in input current.

Although the maximum plastic strain is significantly reduced because of the presence of shield blocks, several solutions could be considered to increase the plastic strain by increasing the input current or creating a notch in the ring or using a smaller height rings than considered in this study. In order to verify and achieve large plastic stain, the same model was investigated with an increased input current. The ordinate values (y values) of the electric current data shown in Figure 3 are scaled by 2.5 times without altering the abscissa values (i.e without changing the frequency of the current), to investigate the influence of the electric current. The triaxiality and Lode parameter results obtained from the new model are shown in Figure 11. The results in Figure 11 show the increase in plastic strain with a stable triaxiality $(\sim 0.33)$ and load parameter $(\sim 1.0)$ that obtained with an increased input current. Although, the triaxiality and Lode parameter fluctuate at low plastic stain due to the biaxial stress, one could consider other options of reducing the height of the ring or using a notch, to closely resemble the required uniaxial stress state to cause failure for a test criterion.

\section{Conclusions}

Suitability of the electromagnetic ring expansion test to fully characterise material at high strain rate is investigated using coupled $3 \mathrm{D}$ numerical modelling. Firstly, the validation of the numerical method was made with the experimental results. After that, stress states were investigated to determine the stress development during the test using the validated model that indicates the development of biaxial stress components and which significantly differ from a uniaxial tensile test cases. It was also identified that the compressive Lorentz force on the ring that influences the stress state and leads to the biaxial nature. Moreover, the biaxiality is significantly apparent in the middle region of the ring as compared to top and bottom edges. Furthermore, the complexity of the stress state increased with the increase in height of the ring. Finally, a shielding mechanism was proposed to avoid the compressive Lorenz force and that enables the development of a stress state closely resembling that during a uniaxial tensile test case. This setup could be used experimentally to characterise materials under high strain rate conditions.

\section{References}

1. L. Meyer, 1st International Conference on High Speed Forming, Institut für Umformtechnik - Technische Universität Dortmund, Dortmund, 2004, pp. 45-56.

2. V. Psyk, D. Risch, B.L. Kinsey, A.E. Tekkaya, M. Kleiner, Journal of Materials Processing Technology, 211 (2011) 787-829.

3. Y.U. Haiping, L.I. Chunfeng, D.E.N.G. Jianghua, Journal of Materials Processing Technology, 209 (2009) 707-713.

4. H. Yu, C. Li, Z. Zhao, Z. Li, Journal of Materials Processing Technology, 168 (2005) 245-249.

5. A. Kapil, A. Sharma, Journal of Cleaner Production, 100 (2015) 35-58.

6. R. Raoelison, M. Rachik, N. Buiron, D. Haye, M. Morel, B. Dos Sanstos, D. Jouaffre, G. Frantz, 5th International Conference on High Speed Forming, Dortmund, 2012, pp. 207-216. 
7. M. Marya, S. Marya, D. Priem, Welding in the World, 49 (2005) 74-84.

8. R. Raoelison, N. Buiron, M. Rachik, D. Haye, G. Franz, M. Habak, Journal of Materials Processing Technology, 213 (2013) 1348-1354.

9. M. Geyer, S. Böhm, IIW Denver Annual Assembly, (2012).

10. R. Raoelison, D. Racine, Z. Zhang, N. Buiron, D. Marceau, M. Rachik, Journal of Manufacturing Processes, 16 (2014) 427-434.

11. C. Pabst, P. Groche, 6th International Conference on High Speed Forming, Institut für Umformtechnik Technische Universität Dortmund, South Korea, 2014, pp. 77-88.

12. R. Raoelison, N. Buiron, M. Rachik, D. Haye, G. Franz, Journal of Manufacturing Processes, 14 (2012) 372-377.

13. M. Marya, S. Marya, Science and Technology of Welding and Joining, 9 (2004) 541-547.

14. R.N. Raoelison, T. Sapanathan, N. Buiron, M. Rachik, Journal of Manufacturing Processes, 20, Part 1 (2015) 112-127.

15. A. Vivek, S. Hansen, B. Liu, G.S. Daehn, Journal of Materials Processing Technology, 213 (2013) 23042311.

16. A. Vivek, B. Liu, S. Hansen, G. Daehn, Journal of Materials Processing Technology, 214 (2014) 15831589.

17. A. Nassiri, G. Chini, A. Vivek, G. Daehn, B. Kinsey, Materials \& Design, 88 (2015) 345-358.

18. Z. Ma, Metallurgical and Materials Transactions A, 39 (2008) 642-658.

19. R.S. Mishra, P.S. De, N. Kumar, Friction stir processing, Springer, 2014.

20. Y. Ahuja, R. Ibrahim, A. Paradowska, D. Riley, Journal of Materials Processing Technology, 217 (2015) 222-231.

21. F. Findik, Materials \& Design, 32 (2011) 1081-1093.

22. P.C. King, S.H. Zahiri, M. Jahedi, Acta Materialia, 56 (2008) 5617-5626.

23. P.C. King, G. Bae, S.H. Zahiri, M. Jahedi, C. Lee, Journal of Thermal Spray Technology, 19 (2010) 620-634.

24. Y. Bao, T. Wierzbicki, International Journal of Mechanical Sciences, 46 (2004) 81-98.

25. J.R. Rice, D.M. Tracey, Journal of the Mechanics and Physics of Solids, 17 (1969) 201-217.

26. T. Wierzbicki, Y. Bao, Y.-W. Lee, Y. Bai, International Journal of Mechanical Sciences, 47 (2005) 719-743.

27. J.R. Johnson, G. Taber, A. Vivek, Y. Zhang, S. Golowin, K. Banik, G.K. Fenton, G.S. Daehn, steel research international, 80 (2009) 359-365.

28. LS-DYNA Keyword User's Manual R8.0, Livermore Software Technology Corporation (LSTC), Livermore, CA, USA, 2015.

29. I. Çaldichoury, P. L'Eplattenier, Electromagnetism and Linear Algebra in LS-DYNA, Livemore Software Technology Corporation, 2012.

30. C. Anderson Jr, I.S. Chocron, A. Nicholls, Journal de Physique IV (Proceedings), EDP sciences, 2006, pp. 331-337.
31. W.H. Hayt, J.A. Buck, Engineering electromagnetics, McGraw-Hill New York, 2001.

32. K. Yang, G. Taber, T. Sapanathan, A. Vivek, G. Daehn, R. Raoelison, N. Buiron, M. Rachik, 7th International Conference on High Speed Forming, Dortmund, 2016, pp. 223-234.

33. A.-C. Jeanson, G. Avrillaud, G. Mazars, G. TABER, G.S. Daehn, F. Bay, N. Jacques, M. Arrigoni, 6th International Conference on High Speed Forming, Institut für Umformtechnik - Technische Universität Dortmund, 2014, pp. 31-36.

34. W.H. Gourdin, Journal of Applied Physics, 65 (1989) 411-422.

35. W. Gourdin, S. Weinland, R. Boling, Review of Scientific Instruments, 60 (1989) 427-432.

36. F.J.P. Reis, A.F.X. C., 11th German LS-DYNA Forum, Ulm, Germany, 2012. 